\title{
THE REAL APPLICATION OF THE SOFTWARE FiLTER SElection Methodology ON Practical ExampleS
}

\author{
Dana Kubatova
}
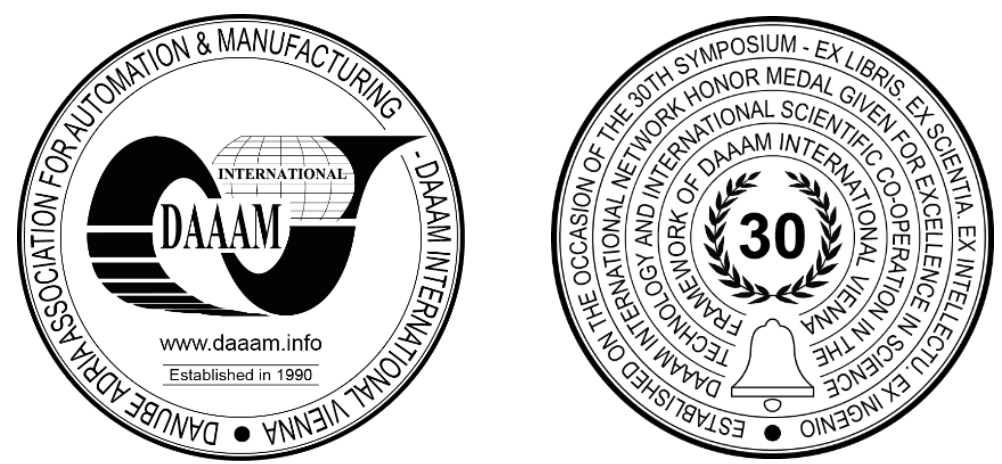

This Publication has to be referred as: Kubatova, D[ana] (2021). The Real Application of the Software Filter Selection Methodology on Practical Examples, Proceedings of the 32nd DAAAM International Symposium, pp.0145-0150, B. Katalinic (Ed.), Published by DAAAM International, ISBN 978-3-902734-33-4, ISSN 1726-9679, Vienna, Austria DOI: $10.2507 / 32$ nd.daaam.proceedings.023

\begin{abstract}
The functional surfaces of components are usually finished by chip and chipless machining methods. The designer prescribes the basic properties of the surface with respect to its intended function. The task of the technology is to implement this prescription. Ideally, in the case of completely error-free production, the finished part is directly ready for functional use. In normal practice, however, the conditions of the production process do not remain completely constant, and it is, therefore, necessary to include inspection operations to detect any deviations that may affect the function of the component (e.g. deviations in dimensions, shape, surface quality, hardness of the component material, etc.). Changes in the manufacturing process affect the surface structure in various ways. Importantly, the measurement of the surface structure not only leads to the determination of the actual surface condition but also provides a basis for the control of the manufacturing process and the prediction of the functional properties of the surface. In the area described in this article, the area of software filter selection in real examples, this is not always the case. And the main reason for this is the low awareness and the high complexity of choosing the appropriate combination of possible procedures and techniques for setting up software filters. In this paper, possible differences in not following the correct measurement procedure, and especially the evaluation of surface roughness, are described. The article does not focus on one particular area of surface roughness measurement but describes the possible differences for both periodic and aperiodic surfaces, depending on the measurement method used (contact or non-contact method).
\end{abstract}

Keywords: Roughness; Methodology of selection of software filter; Aperiodic and periodic surface; Contact and noncontact measuring.

\section{Introduction}

Measurement and evaluation of surface roughness have made significant qualitative progress in recent years. Leading manufacturers of measuring instruments (Hommel, Carl Zeiss, and others) actively responded to the new requirements. This is mainly due to the fact that the surface structure is often checked with the help of single-purpose measuring devices. For this reason, the manufacturers of these machines are also the main creators of pressure to develop standards related to the evaluation of the quality of measurement of machined surfaces. [2] This has ultimately led to improvements in the technologies of existing tools for measuring and evaluating surface structure, as well as to better methods, measuring systems, and surface structure evaluation systems that are still under development. [6;7] 
The surface structure evaluation system is defined by a set of standards that describe the marking, measurement, and evaluation of the surface structure, calibration of measuring instruments, and other aspects. These are GPS (Geometrical Product Specification) standards [5]. In general, the measurement and evaluation of surface structure is a separate area of metrology. Where using special techniques, the data needed to characterize the surface quality can be obtained.

The functional surfaces of the parts are usually finished by methods of chip and chipless machining. The designer prescribes the basic properties of the surface with respect to its intended function. The task of technology is to implement this regulation. In the ideal case of completely flawless production, the finished part is directly ready for functional use. In common practice, however, the conditions of the production process do not remain completely unchanged, and therefore it is necessary to include control operations to detect all deviations that may affect the function of the part (eg deviations in dimensions, shape, surface quality, hardness of part material, etc.). Changes in the production process affect the surface structure in various ways, e.g. the effect of tool wear, the stress in the material, the use of unsuitable cutting conditions, etc. [3], [4] It is important that measuring the surface structure not only determines the actual surface condition, but at the same time, it will also provide data for the regulation of the production process and the prediction of the functional properties of the surface.

Very important properties depend on the quality (quality) of the surface, such as efficiency, reliability, functional properties, external appearance, and finally, the cost of the entire production process. And if there is an inaccurate assessment when evaluating the integrity of the surface, especially when assessing the surface roughness, this can lead to fatal problems in the actual use of the inspected part in practice. To meet all the requirements of surface structure evaluation, it is necessary to keep up with the times and keep under control new possibilities and knowledge in the field of measuring and evaluating surface integrity. And implement this knowledge into real conditions of use.

In the area described in this article, the area of choice of software filters in real examples, this is not always the case. And the main reason is low awareness and great complexity of choosing a suitable combination of possible procedures and techniques for setting software filters. Therefore, a comprehensive methodology for the selection of software filters for both periodic surfaces and subsequently for aperiodic surfaces described in Article 1 was created.

\section{Surface roughness measuring systems}

In today's practice, we find two basic methods of evaluating the surface structure. The older method of surface evaluation is the contact method. It is the most common surface evaluation method that measures the surface profile using high-sensitivity instruments. [8] The contact device means that a specially modified tip scans the coordinates of the evaluated surface, which are then computer-processed. Their disadvantage is that due to the size of the tip $2 ; 5$ or $10 \mu \mathrm{m}$ there is mechanical filtering of the obtained data. (See Figure 1) [9]

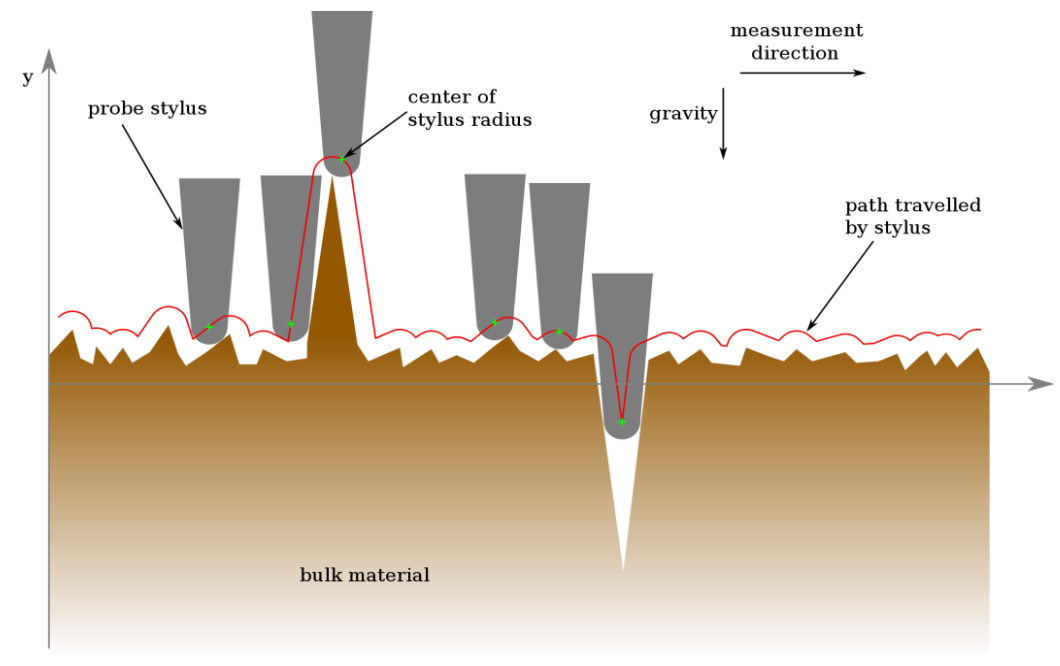

Fig. 1. Contact measurement [9]

This shortcoming has been eliminated by creating surface roughness measurements by non-contact methods. The principle of the non-contact method is based on the use of a light beam, which is projected on a rough surface. The irregularities on the inspected surface created after machining are scattered by the light beam and the light scattering are determined. While with an ideally smooth surface, there is no light scattering, and the beam is reflected as it came. The greater the roughness, the lower the mirror component and the more the scattering components increase. If the height of the irregularities is less than the wavelength of the scattered light, the diffraction vector and the scalar Beckmann theory are used to determine the surface roughness. Only the Gaussian normal distribution is used for the parameters, where precise electromagnetic boundary conditions are obtained due to the difficulty in obtaining the analytical value of the roughness from the light scattering. (see Figure 2) 


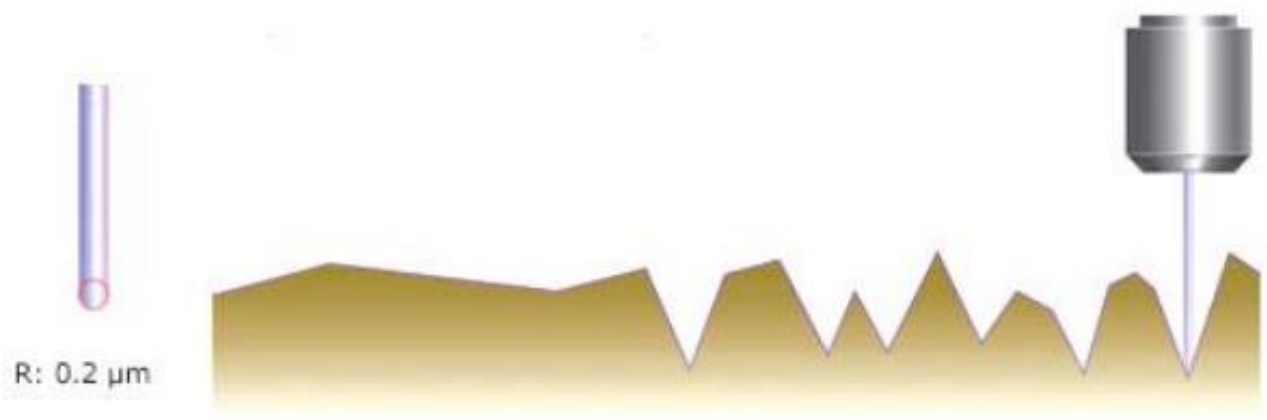

Fig. 2. Non-contact measurement [9]

\section{Brief characteristics of the methodology for the selection of software filters [2]}

In both cases of surface evaluation, however, it is necessary to ensure that the measured data are correctly evaluated and processed. This is much easier thanks to the software filter selection methodology. The software filter selection methodology has 4 (periodic surface) and 5 (aperiodic surface) steps, respectively, thanks to which the user of the profilometer, whether contact or contactless, gets to the correct setting of the device. Furthermore, thanks to the use of the methodology, it should be ensured that two people measure the same or at least in the order of hundredths of the same results (values), which currently does not work completely.

The first step in the methodology of selecting a software filter for a periodic surface is to select the optimal stylus tip size. After summarizing and final evaluation of the tests, it was decided that to achieve optimal results, it is appropriate to use a tip of $2 \mu \mathrm{m}$ for roughness values up to $\mathrm{Ra}=6.3 \mu \mathrm{m}$. In the second step of selecting the software filter for the periodic surface, it is necessary to select the optimal distance between the scanned points. The procedure here is that a compromise must be found between the small variance of the measured value and the value of the distance of the measured value from the standard value.

In the third step, the stylus feed rate is selected when scanning the primary profile. Based on the findings of this test, information emerged that the scan rate has no effect on the Rsm parameter. The results for the parameters Ra, Rv, and Rz using scanning speeds up to $1.07 \mathrm{~mm} / \mathrm{s}$ are almost identical. At higher speeds, the inaccuracy of the measured data increases for all three parameters and increases the variance of values. Therefore, it is not recommended to use a feed rate value greater than $1.07 \mathrm{~mm} / \mathrm{s}$. The fourth (last) step of the methodology is the choice of software filter. Here again, it is important to find a compromise between the smallest variance of values and the maximum measured value.

When creating the methodology for choosing a software filter for an aperiodic surface, it was decided on the basis of the tests performed and described in Articles 2, only to supplement the existing methodology. The methodology was supplemented by one whole step and several other important findings for the evaluation of aperiodic surfaces. The most important thing is to add a step - choose the scanning direction. At this point, the need to measure aperiodic surfaces in several directions per surface trace, at different locations of the test sample, is pointed out. As described in Article [3]. Another important finding for measuring aperiodic surfaces is in the step of choosing a software filter, the finding that compared to the periodic surface came out as the most suitable filter, the filter EN ISO 16610-31 (Gaussian robust filter).

\section{Description of the experiment}

Within the performed experiment, the task was to verify the correct function of the method of software filter selection in the application on selected contact and non-contact measuring devices.

\subsection{Testing samples}

The tested samples were from various applications for the automotive, aerospace, and medical industries. For each tested sample, the optimal conditions for measurement were determined according to the software filter selection methodology described in Article 1, supplemented by new points of the methodology for the aperiodic surface. See Table. 1.

It was always based on four basic areas of software filter selection methodology. So in the first step, the size of the touch was chosen. In the second step, the number of points to be scanned and the scanning direction in which the measurement is to be performed were selected. Which plays a major role for the aperiodic surface. In the third step, the scanning speed and the measured length were selected. Subsequently, the used software filter was selected. In the last step, the parameters suitable for the given application of the part were designed. The choice of the settings described above was always based on the expected surface roughness of the test sample and its intended use. 


\begin{tabular}{|c|c|c|c|c|c|c|c|c|}
\hline $\begin{array}{l}\text { Parameter - } \\
\text { recommende } \\
\text { d setting }\end{array}$ & $\begin{array}{c}\text { Aperiodic } \\
\text { standard }\end{array}$ & $\underset{\text { Flap }}{\text { Longitudinally }}$ & $\underset{\text { Flap }}{\text { Longitudinally }}$ & Engine & Form & $\begin{array}{l}\text { Spraying } \\
\text { before }\end{array}$ & $\begin{array}{l}\text { Spraying } \\
\text { after }\end{array}$ & $\begin{array}{l}\text { Mirror } \\
\text { surface }\end{array}$ \\
\hline $\begin{array}{l}\text { Expected } \\
\text { roughness }\end{array}$ & $0.2 \mu \mathrm{m}$ & to $\mathrm{Ra}=15 \mu \mathrm{m}$ & to $\mathrm{Ra}=10 \mu \mathrm{m}$ & $\mathrm{Ra}=1 \mu \mathrm{m}$ & $\begin{array}{c}\text { to } \mathrm{Ra}=0,8 \\
\mu \mathrm{m}\end{array}$ & $\begin{array}{c}\text { to } R a=3,2 \\
\mu \mathrm{m}\end{array}$ & to $\mathrm{Ra}=1 \mu \mathrm{m}$ & $\begin{array}{c}\text { DtoRa }=0,2 \\
\mu \mathrm{m}\end{array}$ \\
\hline Tip size & $2 \mu \mathrm{m}$ & $2 \mu \mathrm{m}$ & $2 \mu \mathrm{m}$ & $2 \mu \mathrm{m}$ & $2 \mu \mathrm{m}$ & $2 \mu \mathrm{m}$ & $2 \mu \mathrm{m}$ & $2 \mu \mathrm{m}$ \\
\hline $\begin{array}{l}\text { Scanning } \\
\text { direction }\end{array}$ & $\begin{array}{c}\text { different } \\
\text { directions }\end{array}$ & $\begin{array}{c}\text { different } \\
\text { directions }\end{array}$ & One direction & $\begin{array}{c}\text { One } \\
\text { direction }\end{array}$ & $\begin{array}{c}\text { different } \\
\text { directions }\end{array}$ & $\begin{array}{c}\text { different } \\
\text { directions }\end{array}$ & $\begin{array}{c}\text { different } \\
\text { directions }\end{array}$ & $\begin{array}{c}\text { different } \\
\text { directions }\end{array}$ \\
\hline $\begin{array}{c}\text { Number of } \\
\text { points }\end{array}$ & 48000 & 6858 & 4572 & 48000 & 16000 & 4800 & 4800 & 48000 \\
\hline $\begin{array}{c}\text { Measured } \\
\text { length }\end{array}$ & $4.8 \mathrm{~mm}$ & $4.8 \mathrm{~mm}$ & $3.2 \mathrm{~mm}$ & $4.8 \mathrm{~mm}$ & $4.8 \mathrm{~mm}$ & $4.8 \mathrm{~mm}$ & $4.8 \mathrm{~mm}$ & $4.8 \mathrm{~mm}$ \\
\hline Feed rate & $0.5 \mathrm{~mm} / \mathrm{s}$ & $0.5 \mathrm{~mm} / \mathrm{s}$ & $0.5 \mathrm{~mm} / \mathrm{s}$ & $0.3 \mathrm{~mm} / \mathrm{s}$ & $0.5 \mathrm{~mm} / \mathrm{s}$ & $0.5 \mathrm{~mm} / \mathrm{s}$ & $0.5 \mathrm{~mm} / \mathrm{s}$ & $0.5 \mathrm{~mm} / \mathrm{s}$ \\
\hline Cuf-off & $0.25 \mathrm{~mm}$ & $2 ., 5 \mathrm{~mm}$ & $0.8 \mathrm{~mm}$ & $0.25 \mathrm{~mm}$ & $0.8 \mathrm{~mm}$ & $0.8 \mathrm{~mm}$ & $0.25 \mathrm{~mm}$ & $0.25 \mathrm{~mm}$ \\
\hline $\begin{array}{l}\text { Software } \\
\text { filter }\end{array}$ & $16610-31$ & 4768 & 4768 & $16610-31$ & $16610-21$ & 4768 & $16610-31$ & $16610-31$ \\
\hline $\begin{array}{c}\text { Evaluated } \\
\text { parameters }\end{array}$ & $\begin{array}{c}\text { Pa, Pz, Rk, } \\
\text { Rvk, Rpk, } \\
\text { Mr1, } \\
\text { Mr2,Ra, } \\
\text { Rz, Rv }\end{array}$ & $\begin{array}{c}\mathrm{Pa}, \mathrm{Pz}, \mathrm{Rk} \\
\mathrm{Rvk}, \mathrm{Rpk}, \mathrm{Mr} 1 \\
\mathrm{Mr} 2, \mathrm{Ra}, \mathrm{Rz} \\
\mathrm{Rv}\end{array}$ & $\begin{array}{c}\mathrm{Pa}, \mathrm{Pz}, \mathrm{Rvk}, \\
\text { Rpk, Mr1, } \\
\text { Mr2,Ra, Rz, } \\
\text { Rv }\end{array}$ & $\begin{array}{c}\text { Ra, Rz, Rt, } \\
\text { Rp, Rvk, } \\
\text { Rpk, Mr1, } \\
\text { Mr2, }\end{array}$ & $\begin{array}{c}\text { Ra, Rv, Rp, } \\
\text { Rk, Rvk, } \\
\text { Rpk, Mr1, } \\
\text { Mr2, }\end{array}$ & $\begin{array}{l}\text { Ra, Rv, Rp, } \\
\text { Rk, Rvk, } \\
\text { Rpk, Mr1, } \\
\text { Mr2, }\end{array}$ & $\begin{array}{l}\text { Ra, Rv, Rp, } \\
\text { Rk, Rvk, } \\
\text { Rpk, Mr1, } \\
\text { Mr2, }\end{array}$ & $\begin{array}{l}\text { Ra, Rq, Rk, } \\
\text { Rvk, Rpk, } \\
\text { Mr1, Mr2, }\end{array}$ \\
\hline
\end{tabular}

Table 1. Recommended parameters for measurement based on the methodology of software filter selection

\subsection{Tested devices}

1) Contact devices - from the area of contact surface roughness measurement, both measurements on laboratory devices and on devices intended for workshop measurements were considered. Each of these devices has its pros and cons that enter into the measurement, and it is necessary to take them into account.

a. Hommel Etamic T8000 Roughness Tester - is one of the most widespread profilometers/roughness gauges in the world. I use them both for common surface roughness measurements and it is very widely used for calibration of bound roughness standards. Its undeniable advantage is its variability of settings. Whether in the field of software filters or in the field of the possibility of evaluating an inexhaustible range of roughness parameters up to the possibility of exchanging a stylus of various sizes or shapes.

b. Workshop roughness meter Mitutoyo SURFTEST SJ-410 - is a workshop roughness tester, which due to the impossibility of replacing the probe has only limited use but in the case of a suitably selected tip when buying the device based on the product portfolio, for which it will be intended laboratory instruments. [10]

2) Non-contact instruments - for the test described in this article, consideration was given to instruments that are used primarily to measure surface roughness and measure using laser surface sensing. Thus, instruments that can also be used for measuring dimensions and sensing the surface are performed by illuminating with light in a plan view.

a. Optical-scanning microscope IFM G4 (Alicona) - the device works on the principle of scanning the surface with a laser beam through objectives, which performs a magnification of the surface so that it can be evaluated. The disadvantage of the instrument is that it allows measurement with only one present software filter. [11]

b. Kyence VHX-6000 - the instrument is a compact measuring microscope which is used not only to measure the dimensions but is also a good alternative to instruments used exclusively for measuring surface roughness.

c. Olympus LEXT OLS5000 laser microscope - the instrument falls into the field of confocal microscopes. Thanks to the appropriately selected objectives, working with the microscope is very simple and fast.

\section{Test results}

The actual evaluation of the functionality of the methodology was started by an experiment in which the measured data from different devices were compared but using the same conditions determined according to the methodologies. For these purposes, measurements were performed on a standard piece for which the value of selected parameters is known. The measured data can be seen in Table 2. This table shows the achieved values for the tested standard with an aperiodic surface. The nominal value of the standard is $\mathrm{Ra}=0.2 \mu \mathrm{m}$. This value was chosen quite intentionally, given that it is the limit value for some selected devices for the test. 


\begin{tabular}{|c|c|c|c|c|c|}
\hline & Hommel & Mitutoyo & IFM & LEXT & VHX-600 \\
\hline Pa $[\boldsymbol{\mu m}]$ & 0.2 & 0.22 & 0.25 & 0.2 & 0.21 \\
\hline Pz $[\boldsymbol{\mu m}]$ & 0.49 & 0.48 & 0.53 & 0.54 & 0.5 \\
\hline Rk $[\boldsymbol{\mu m}]$ & 0.23 & 0.25 & 0.27 & 0.28 & 0.25 \\
\hline Rvk $[\boldsymbol{\mu m}]$ & 0.06 & 0.059 & 0.062 & 0.062 & 0.061 \\
\hline $\operatorname{Rpk}[\boldsymbol{\mu m}]$ & 0.06 & 0.056 & 0.064 & 0.064 & 0.063 \\
\hline Mr1 [\%] & 13.713 & 13.701 & 13.816 & 13.796 & 13.805 \\
\hline Mr2 [\%] & 93.426 & 93.469 & 93.526 & 93.396 & 93.416 \\
\hline $\operatorname{Ra}[\boldsymbol{\mu m}]$ & 0.2 & 0.22 & 0.25 & 0.2 & 0.21 \\
\hline $\operatorname{Rz}[\boldsymbol{\mu m}]$ & 0.49 & 0.48 & 0.53 & 0.54 & 0.5 \\
\hline $\operatorname{Rv}[\boldsymbol{\mu m}]$ & 0.24 & 0.25 & 0.27 & 0.28 & 0.25 \\
\hline
\end{tabular}

Table 2. Measured values from the standard

Already the initial measurement pointed out some small differences in the measured results, but based on the difference between the meters, the differences were expected. Given that the differences between the plots were up to $5 \%$ of the difference, it was decided to continue the test. The evaluation of the test was performed based on a comparison of the achieved (measured) results for individual measuring systems, their use, and the character of the required surface. The disadvantage is, as already described above, that not all devices are able to measure according to all software filters. But even so, it was possible to build the possibilities of use and the expected results achieved.

1) Contact roughness meter

a. Roughness meter Mahr MarSurf LD 120 - allows using the methodology in the whole range when achieving results with a deviation of up to $5 \%$ (the size of measurement uncertainty) in the resulting measured value. This was found by cross comparing the results with the collaborating laboratory.

b. Mitutoyo SURFTEST SJ-410 workshop roughness tester - the device allows the use of only part of the methodology because the device has only a limited number of software filters, a fixed measurement speed, including the distance between points and a fixed one specific tip. But in cases where it was possible to make a comparison based on the recommendations, values with a maximum deviation of up to $5 \%$ were again achieved.

2) Non-contact roughness meter

a. Optical-scanning microscope IFM G4 (Alicona) - the device does not allow changing the software filter based on the user's request, only changing parameters. The device has a fixed filter 16610-21, based on this it was not possible to verify whether the methodology works on this device.

b. Laser microscope OLS5000 - LEXT - allows to use the methodology in the whole range to achieve results with a deviation of up to $10 \%$ (usually higher roughness values, which is due to the laser scanning system, which has a diameter of $0.2 \mu \mathrm{m}$ in its entire length compared to touch sensing where the tip has a radius of $2 \mu \mathrm{m})$ in the resulting measured value. This was found by cross comparing the results with the collaborating laboratory.

c. Kyence VHX-6000 - allows using the methodology in the whole range when achieving results with a deviation of up to $10 \%$ (usually higher values of roughness, which is caused by a laser beam scanning system, which has a diameter of $0.2 \mu \mathrm{m}$ in its entire length compared to touch sensing where the tip has a radius of $2 \mu \mathrm{m}$ ) in the resulting measured value. This was found by cross comparing the results with the collaborating laboratory.

\section{Conclusion}

We define texture, or in other words the structure of a surface, as an area with a huge set of grains, which are located between the surroundings and the surface of the material, ie a fixed part. The surface is an extremely complex system, where there are repeated (periodic) or random (aperiodic) deviations from the ideal geometric shape of the surface. These deviations can be expressed in several ways, the oldest is the line profile, and the most common nowadays is probably the expression of the three-dimensional topography of the surface. According to the size of the pitch of the respective irregularities, the surface structure is divided into three components. The basic profile determines the component with the largest pitch of inequalities and is called the P-profile.

The component with the smallest pitch is determined by the surface roughness, which in turn is referred to as the Rprofile. And the component between the largest and smallest spacing is called the surface ripple, W-profile. [3], [9]. The composition of these components on the surface generally directly affects the functional properties of the surface. The often-expressed view of the surface - "the smoother, the better" - may not always be correct, as there are other factors. E.g., to ensure lubrication, depressions must be left on the surface to hold the lubricating medium. 
In all cases, it is necessary to assess the economic side of things - the increase in the cost of producing a very "smooth" surface may not always correspond to the functional benefit. Therefore, functional use is decisive for the properties of the surface. The requirements for surfaces that will move relative to each other will be different from the requirements for surfaces forming sealing surfaces or for surfaces intended for subsequent painting, etc. It follows from the above that measuring and evaluating the surface structure is very important from a practical point of view.

And ensuring the correct measurement procedure is very demanding and complicated. Mainly due to the very large possible variation of possible settings that the control device can allow. However, the article aims to reduce at least a small part of this possible variability and, thanks to the described methodology and demonstration of the achieved results, outline the recommended roughness setting in evaluating selected typical situations in evaluating surface roughness in the automotive, aerospace, or medical industries.

As can be read from the article, based on the tests performed while adhering to the methodology of software filter selection, whether the periodic or non-periodic surface is already measured, it is possible to achieve almost identical results despite the different instruments used in the measurement. For contact devices, the difference between the measured values is up to $5 \%$, for optical devices, this value of the difference in the measured values is up to $10 \%$. Which are extreme values and in most of the performed tests the differences were in the order of 2 to $3 \%$.

\section{Acknowledgments}

The paper was created with the support of the Motivation System of the University of West Bohemia in Pilsen, part of POSTDOC. And it was co-financed by project GA UWB in Pilsen: SGS-2019-008 "Research and development for innovation in the field of manufacturing processes - Technology of metal cutting III".

\section{References}

[1] Kubátová, D.; \& Melichar, M. (2018) Post Processing of Roughness Raw Data Solid State Phenomena 278 15-22 https://doi.org/10.4028/www.scientific.net/ssp.278.15

[2] Kubatova, D. (2018) Software surface roughness filters V Plzni Disertační práce (Ph.D.). Západočeská univerzita v Plzni, Fakulta strojní.

[3] Kubátová D (2020) Problems of defining and subsequently measuring surface roughness in aperiodic surfaces Proceedings of the 31st DAAAM International Symposium pp. xxxx-Xxxx, B. Katalinic (Ed.), Published by DAAAM International, ISBN 978-3-902734-xx-x, ISSN 1726-9679, Vienna, Austria, DOI: 10.2507/31st.daaam.proceedings.Xxx

[4] Cekic, A.; and Muhamedagic, K.; and Cohodar. M.; and Begic-Hajdarevic, D.; and Biogradlija, S. (2019) Experimental Investigation of Effect of Overhang Tool Length on Tool Vibration and Surface Roughness Proceedings of the 30th DAAAM International Symposium pp.0184-0191 B. Katalinic (Ed.), Published by DAAAM International, ISBN 978-3-902734-22-8, ISSN 1726-9679, Vienna, Austria DOI: 10.2507/30th.daaam.proceedings.024

[5] Kubatova, D.; and Melichar, M. (2019) Roughness Evaluation Using Abbott-Firestone Curve Parameters, Proceedings of the 30th DAAAM International Symposium, pp.0467-0475, B. Katalinic (Ed.), Published by DAAAM International, ISBN 978-3-902734-22-8, ISSN 1726-9679, Vienna, Austria DOI: 10.2507/30th.daaam.proceedings.063

[6] EN ISO 4287. Geometrical product specifications (GPS) - Surface structure: Profile method Terms, definitions and parameters of surface structure. 1. Brusel: CEN, 1999. [7] EN ISO 3274. Geometrical product specifications (GPS) - Surface structure: Profile method - Nominal characteristics of tactile devices. 1. Brusel: CEN, 1999

[7] Chen, S.; and Feng, R.; and Zhang, Ch.; and Zhang, Z.; Surface roughness measurement method based on multiparameter modeling learning. Measurement [online]. 2018, 129, 664-676 [cit. 2020-09-09]. DOI: 10.1016/j.measurement.2018.07.071. ISSN $02632241 . \quad$ Dostupné z: https://linkinghub.elsevier.com/retrieve/pii/S0263224118307103

[8] Purkait, B.; and Majumdar, D, D.; and Mazumder, R.; (2017) Bed roughness and grain sorting- an experimental study over fine to medium sand beds; International Journal of Sediment Research; Volume 32; Issue 3; Pages 384 400 ISSN 1001-6279 https://doi.org/10.1016/j.ijsrc.2017.06.002.

[9] Chen, S.; Feng, R.; Zhang, Ch.; and Zhang, Y. (2018) Surface roughness measurement method based on multiparameter modeling learning. Measurement [online]. 129, 664-676 [cit. 2020-09-09]. DOI: 10.1016/j.measurement.2018.07.071. ISSN 02632241.

[10] Purkait, B.; Majumdar, D. D.; Mazumder, R.; (2017) Bed roughness and grain sorting- an experimental study over fine to medium sand beds, International Journal of Sediment Research, Volume 32, Issue 3, Pages 384-400, ISSN 1001-6279, https://doi.org/10.1016/j.ijsrc.2017.06.002.

[11] Zatloukal, T.; Gombar, M.; Fulemova, J.; Rehor, J. \& Povolny, M. (2019). Optimization of the Thermal Spraying Process Depending on the Surface Roughness, Proceedings of the 30th DAAAM International Symposium, pp.10261033, B. Katalinic (Ed.), Published by DAAAM International, ISBN 978-3-902734-22-8, ISSN 1726-9679, Vienna, Austria DOI: 10.2507/30th.daaam.proceedings.143 